\title{
Modelling Road User Perceptions towards Safety, Comfort, and Chaos at Shared Space: The via Maqueda Case Study, Italy
}

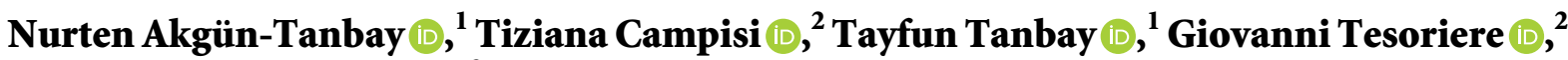 \\ and Dilum Dissanayake ${ }^{3}{ }^{3}$ \\ ${ }^{1}$ Faculty of Engineering and Natural Sciences, Bursa Technical University, Bursa 16330, Turkey \\ ${ }^{2}$ Faculty of Engineering and Architecture, University of Enna Kore, Enna 94100, Italy \\ ${ }^{3}$ School of Engineering, Newcastle University, Newcastle, UK \\ Correspondence should be addressed to Tiziana Campisi; tiziana.campisi@unikore.it
}

Received 8 August 2021; Revised 11 December 2021; Accepted 14 December 2021; Published 7 January 2022

Academic Editor: Jaeyoung Lee

Copyright (C) 2022 Nurten Akgün-Tanbay et al. This is an open access article distributed under the Creative Commons Attribution License, which permits unrestricted use, distribution, and reproduction in any medium, provided the original work is properly cited.

\begin{abstract}
This study aims to investigate the impacts of perception of infrastructure, sociodemographic characteristics, frequency of road use, and road user perception on safety, comfort, and chaos with respect to shared spaces. The case study area was the Via Maqueda, a shared street in Palermo, Italy. A face-to-face survey was conducted and the answers of 200 of the participants, who use three active travel modes, namely, walking, cycling, and micromobility, were analysed. The results obtained from the ordered logit models suggest that one-unit higher perception of infrastructure will increase safety and comfort perceptions for both walking and cycling. Females feel less safe while walking and less comfortable while cycling at shared spaces compared to males. Increasing the age group by one unit will decrease the safety and comfort perceptions for walking. The participants who use the shared spaces more frequently perceive that they feel more comfortable with cycling. Participants, particularly males, find the shared spaces less chaotic for walking when the perception of infrastructure is higher. Regarding the micromobility use at shared spaces, females feel less comfortable compared to males while using micromobility.
\end{abstract}

\section{Introduction}

Shared space is an urban transport strategy, which aims to improve the mobility of pedestrians, cyclists, and vehicles by regulating interactions in a segregated or unsegregated manner. A segregated route differs from an unsegregated route in that the pedestrians and cyclists and vehicles are separated from each other by a physical feature [1]. Shared spaces help transport planners to organize different types of modes in a certain space and to limit speeds [2]. Although separating transport modes is a common method to improve the safety perception of road users [3] and shared spaces can increase conflicts, the shared space approach has the potential to decrease the risks as a result of limited speeds [4].

In the last two decades, urban shared spaces have spread in cities all over Europe, particularly in the Netherlands, Denmark, Sweden, and Germany. Shared spaces have several advantages such as reducing the dominance of motor vehicles, traffic congestion, parking problems, and transport emissions $[5,6]$. These spaces are still accessible to private motor vehicles; however, the vehicles are forced to reduce their speed. This provides a benefit not only to vulnerable users but also to the drivers themselves [7]. Since shared spaces motivate road users to utilize active transport modes, these infrastructures can be considered as an essential element of sustainable urban mobility planning. Active transport modes of walking and cycling offer benefits in the context of health, energy, economy, and environment $[8,9]$. These benefits are demonstrated in survey studies [10-13]. In shared spaces, designers have attempted to establish a controlled and limited presence of vehicles, and increase the full presence of pedestrians and cyclists [14]. There is an interest in pedestrian-cyclist-oriented shared space, since public space for all road users is limited in the case of 
separated infrastructures, and a sustainable transport system necessitates the promotion of active transport modes of walking and cycling [15].

1.1. Limitations of Shared Spaces. Shared spaces have disadvantages and limitations as well as advantages. A shared space is not as controlled as separated paths and consequently users' interactions and speed differentials cause inconsistencies [3]. Sharing of the same facilities by high volumes of vulnerable road users can cause conflicts and uncomfortable feelings [3, 16, 17]. A former study [18] underlined that pedestrians do not feel comfortable while using shared space if their existence is not clear to other road users, and clear visibility is mainly related to a high level of infrastructure. Moreover, pedestrians tend to have a negative attitude while sharing the space with cyclists, but an appropriate infrastructural design can eliminate this negative behaviour [19].

Safety is an important consideration for pedestrians, cyclists, and micromobility users as they are subjected to more traffic accidents compared to private cars and buses. A survey-based study in Sydney, Australia, by Hatfield \& Prabhakharan [20] identified that inappropriate positioning, cyclists' speeding, and/or distraction and failure to give way to pedestrians reveal critical safety problems. It was stated that cyclists mostly fail to fulfil their responsibilities while using shared space such as keeping a distance, slowing, and warning when passing pedestrians [20]. On the other hand, pedestrians commonly use mobile phones and MP3 players while sharing spaces with other travel modes. In such cases, safety emerges as a critical parameter when designing the shared spaces. A former study [21] points out that physical barriers, such as vendor booths or garbage bins, limit pedestrian movements and increase violation by pedestrians. The safety issues can also be critical, and collisions between cyclists and pedestrians may cause a serious level of severities [22]. Both cyclists and pedestrians agree that crowding and pedestrians' failure to pay attention are major contributing factors to severities [3]. To recapitulate, infrastructure and road user perceptions emerge as important factors in order to eliminate hazardous issues at shared spaces.

Many researches thus far in this area focus on safety and comfort issues between cyclists and pedestrians at shared spaces. However, there is limited knowledge and understanding on safety for micromobility users at shared spaces. The increase of micromobility use in shared spaces also causes several discomforts and unsafe situations for active travellers, particularly pedestrians [23]. As mentioned by Che, Lum \& Wong [24], overtaking a pedestrian by an e-scooter user is safer when the speed is lower than $10 \mathrm{~km} / \mathrm{h}$. Pedestrians feel less safe than e-scooter users at shared spaces since pedestrians are more vulnerable compared to e-scooter users.

1.2. Perception of Infrastructure. The permanent solution is to segregate all active travel modes from each other to enhance safety and comfort measures; however, segregated infrastructure is not always applicable [3]. Also, segregation is against the fundamental understanding of shared space designs. Despite the fact that safety and comfort are issues for all vulnerable road users, current urban development and economic limitations do not allow to provide a separate path for each travel mode. Therefore, shared spaces can provide a solution to deal with the limitations of modern cities [9]. Vulnerable road users are encouraged to use shared spaces, particularly in built environments [25]. Eliminating the safety, comfort, and chaos issues can enhance the advantages of shared spaces. Improving the infrastructural level of service by applying appropriate methods is important to pave the way for the coexistence of active travel modes $[22,26]$. Therefore, former studies [9, 26-28] focused on the impact of the level of service on safety and comfort measures for active travel modes at shared spaces.

Level of service (LOS) is a quantitative methodology for assessing the quality of infrastructure that is introduced by the Highway Capacity Manual [29]. There are six levels from A to $\mathrm{F}$ in this classification, with A describing the highest and $\mathrm{F}$ describing the lowest infrastructure levels. It was argued that LOS is a critical parameter in order to evaluate the safety level for active road users at shared spaces [9]. Infrastructure assessment is a key element for adequate planning of shared spaces, and LOS is a convenient indicator for a holistic evaluation. However, Parks et al. [30-32] performed a comparative study between three bicycle LOS models and found that the methodology presented by the Highway Capacity Manual [29] was insufficient. LOS of the shared space is related to the road user density. Higher density reduces the LOS rating; nevertheless, a high LOS for shared space does not guarantee a high level of safety and comfort for a user [33]. In fact, a high LOS may be a consequence of the users' unwillingness to use the infrastructure [34]. Therefore, a recent study shows that pedestrian LOS models shift from quantitative approaches that focus on the density and flow to qualitative and quantitativequalitative mixed techniques, which also consider user perception and the built environment [35]. Recent research related to pedestrians and walkability discusses the importance of considering both actual and perceived safety risks for policy-making [36, 37]. The concept of quality of service (QOS) can be considered as an extension of LOS since it takes into account the viewpoint of the road users [29]. Rodriguez-Valencia et al. [38] proposed a pedestrian QOS methodology by using the data of 30 infrastructures and carrying out surveys to consider user perception in Bogota, Colombia, and the results showed that including user perceptions improves the assessment capability of the QOS model. Therefore, QOS can be considered as a combination of LOS and road users' perception of infrastructure. LOS already can be calculated using the traffic and infrastructural parameters. The uncertainty in analysing the quality of an infrastructure of a specific study area is the lack of detailed information on the perception of road users on infrastructure. Therefore, the studies on shared spaces should focus on user perception of infrastructure in order to obtain a more accurate prediction of QOS.

Nikiforiadis \& Basbas [26] carried out an analysis and stated that several parameters have an influence on 
pedestrians' and cyclists' perceived LOS at shared spaces. Sociodemographic characteristics (i.e., gender and age) statistically and significantly influence LOS perceptions among safety perspectives [27]. In brief, sociodemographic characteristics should be considered in further studies. In addition, the existence of bicycles on shared spaces affects pedestrians' perceived LOS [28]. In summary, the infrastructure and sociodemographic characteristics play a key role in perceived safety and comfort measures at shared spaces.

1.3. Research Gap, Aim, and Objectives. Safety, comfort, and chaos are increasingly becoming apparent as vital factors for shared space development and encouraging communities to use this infrastructure. Currently, it is well known that several issues, such as failure to give way, speeding, physical limitations on space (i.e., garbage bins and vendor booths), and overtaking, are barriers for all active travel modes at shared spaces. In addition, a well-designed infrastructure of shared space emerges as an important issue in addressing these problems. Although this approach is highly important, it suffers from a lack of knowledge in safety, comfort, and chaos in this novel concept of shared space, as well as transport user perceptions in them and, more importantly, how sociodemographic characteristics and perception of infrastructure influence these parameters. Beyond this, there is a significant gap in the literature about micromobility users at shared spaces, since this active travel mode has only recently become popular in modern cities.

This study aims to investigate the influence of perception of infrastructure, sociodemographic characteristics, and travel frequency on road users' safety, comfort, and chaos perception in the shared street Via Maqueda, Palermo. The objectives of the research are as follows:

(1) To predict impacts of perception of infrastructure, sociodemographic characteristics, and frequency of travel on transport user perception towards safety, comfort, and chaos with attention to walking, cycling, and micromobility.

(2) To estimate the influences of sociodemographic characteristics and road use frequency on perception of infrastructure at shared space.

(3) To identify the most appropriate statistical methods and apply them for the prediction analysis.

\section{Materials and Methods}

The aim of this study was to explore the transport user perception on safety, comfort, and chaos with attention to shared urban streets. The case study area was the shared street Via Maqueda in the city of Palermo, Italy, which is one of the oldest touristic and commercial roads in the Sicilian metropolis (Figure 1). The $2 \mathrm{~km}$ long Via Maqueda Street was converted to an inaccessible road for private motor vehicles except for police or disabled people and became a shared space for cyclists, pedestrians, and micromobility users. The street is a segregated shared space and the

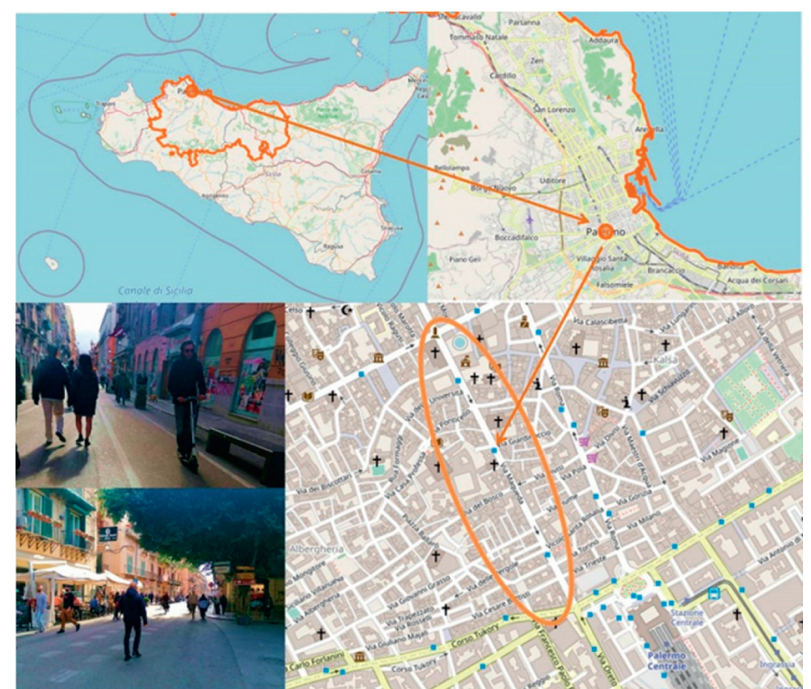

Figure 1: Case study area: Via Maqueda, Palermo, Italy (Source: Google Maps).

demarcation is applied with surface marking. On both sides of the street, there were two pavements about $1.40 \mathrm{~m}$ wide, which often cannot be used by pedestrians because there are stalls or improvised activities. There are also benches and street furniture along the edges of the road, which can be easily used by people.

The Via Maqueda street has been frequently used on a daily basis by inhabitants and tourists since numerous offices, commercial activity places, and architectural attractions were present. The maximum pedestrian flow on this street was approximately $1200 \mathrm{ped} / \mathrm{h}$ during weekdays before the COVID-19 pandemic. However, the pedestrian flow dropped to $700 \mathrm{ped} / \mathrm{h}$ during the postlockdown phase. The use of bicycles ( 90 bicycles/h) and micromobility vehicles (30 scooters/h) have not changed compared to before and during the postlockdown phase.

Face-to-face interviews were conducted which offered several advantages such as exploring complex issues since the interviewer can give fuller explanations of questions, motivating the respondents to reply to the survey questions accurately [39]. The survey with face-to-face interviews on the street made it possible to exactly intercept the target we are looking for: it is precisely the location of the interviewer; therefore, it was possible to collect data with respect to a specific category of street user. In this study, the survey was carried out during 15 working days starting from 22 May 2020. The interview took 10-15 minutes per respondent and was conducted by two interviewers.

The perception of a road user having experience in using different transport modes may not be the same as that of a road user having experience in using a single mode of transport. Therefore, the target of this research was to analyse the safety, comfort, and chaos perceptions of people who have experience (i.e., actively using the mode for transport purposes) of all three travel modes namely walking, cycling, and micromobility in the shared case study area. A total of 653 road users were asked to answer the questionnaire, $70 \%$ of whom (457 respondents) were 
available to reply to the survey questions, while $30 \%$ declined due to being afraid of COVID-19 infection, being late to work, or other reasons. 457 road users were asked whether they had experience with all three transport modes, and 200 of them responded that they had an experience on walking, cycling, and micromobility at the shared case study area. Therefore, the answers of these 200 respondents were considered in the analysis. The relationship between population and sample size and margin of error can be expressed by the relation of Krejcie and Morgan formula [40] as follows:

$$
n=\frac{\chi^{2} N p(1-p)}{e^{2}(N-1)+\chi^{2} p(1-p)}
$$

where $n$ and $N$ are the sample and population sizes, respectively, $e$ is the margin of error, $\chi$ is the value of the chisquare distribution having a degree of freedom of one at a certain confidence level, and $p$ is population proportion.

The number of survey participants is 200 and Palermo's population is 647422 [41]. Equation (1) gives a margin of error value of $\mp 6.9 \%$ when $p=0.5$ and the confidence interval is $95 \%$, which gives a chi-square value of $\chi^{2}=3.841$. Although a margin of error of $\pm 5 \%$ is considered as acceptable in survey studies, this error can have a value of $\pm 6.4 \%$ in perception-related research [42], and it can go up to $\pm 25 \%$ in extreme cases [43].

The survey covered several important areas including sociodemographic characteristics (i.e., gender and age group), frequency of road use, and perception of infrastructure (Table 1). Questions were also included to gather road user perception on safety, comfort, and chaos with respect to walking, cycling, and micromobility. The term chaos was used to identify the disorganization of the shared street, Via Maqueda. The responses for safety, comfort, and chaos perceptions were collected based on Likert scale ranging from 1 to 5 ( $1=$ completely disagree, $2=$ disagree, $3=$ moderate, $4=$ agree, $5=$ completely agree).

The question "How do you evaluate the level of service of infrastructure?" was asked to determine the parameter, namely, perception of infrastructure ranked from $\mathrm{A}$ to F. This approach was used in the former studies. A statistical modelling based pedestrian LOS assessment methodology was proposed by Landis et al. [44], in which 75 pedestrians were asked to evaluate sidewalks with different conditions for safety and comfort, on a ranking of A-F. Similarly, based on the perception of 150 cyclists, Landis et al. [45] proposed a bicycle LOS model to evaluate the cycling infrastructure on a scale of $\mathrm{A}-\mathrm{F}$.

As recommended in the literature [46], the analysis started with descriptive statistics in order to illustrate the characteristics of the dataset. Regarding the aim of the study, the outcome variable in the predictive models was in ordinal scale, such as transport user perception on safety, comfort, and chaos (ranked from 1 to 5). Ordinal scale variables sometimes confuse the researcher in choosing the correct predictive model. For instance, sequential ordinal data may mislead the researcher to apply linear regression. However, former studies suggested that conducting a linear regression was not suitable in such cases [47, 48]. If the outcome variable is in ordinal scale in a predictive analysis, such as "very high, high, medium, low, very low," the type of regression model should be ordinal [49]. Ordinal regression models have been widely used in former transport studies in order to estimate the influence of predictor variables on an ordinal outcome variable [50]. For instance, Kang and Lee [51] developed a statistical cycling LOS model through ordinal regression by using the response of 198 cyclists about their perceptions. Bai et al. [52], also carried out a user perception-based study to develop a statistical cycling LOS methodology with the ordinal regression. Therefore, the analysis in this study is continued by applying the ordered logit method to develop a predictive model. If there are $k+1$ ordered categories then the ordered logistic model is defined as [53]

$$
\begin{aligned}
\log i t(Y \leq i) & =\ln \left(\frac{P(Y \leq i)}{1-P(Y \leq i)}\right) \\
& =\alpha_{i}+\beta_{i 1} X_{1}+\ldots+\beta_{i m} X_{m}, i=1, \ldots, k
\end{aligned}
$$

where $i=1, \ldots, k$ is a specific category, $P(Y \leq i)$ is the cumulative logits for the ordinal response variable $Y, \alpha_{i}$ are the intercepts, $\beta_{i j}$ are the logistic coefficients, $X_{j}$ are predictor variables, and $m$ denotes the number of predictors.

In summary, a methodological framework is presented in Figure 2. The following sections present the results of the analysis and the discussion with some useful suggestions and recommendations to future studies and policy makers.

\section{Results}

The statistical analysis was carried out by using STATA software. The descriptive statistics are illustrated in Table 2. The results showed that the number of male and female participants was approximately equal in the survey study. In addition, the participants belonged to a wide range of age groups. This suggested that the results in the further prediction analysis were unbiased because the participants were represented by different sociodemographic groups.

The participants were familiar with the case study area because the majority of them were using the area frequently and $40 \%$ of them were traveling on this street every day. Regarding the perception of infrastructure, around $84 \%$ of the participants found that the infrastructure was above level C. This suggested that the majority of the participants found the infrastructure of the case study street to be moderate. However, a very low percentage of participants (with 6.5\%) ranked the infrastructure level as Level $\mathrm{A}$.

The descriptive statistics also covered the road user perceptions on walking, cycling, and using micromobility while having a trip on a shared street. These concerns were associated with safety, comfort, and chaos for each travel alternative. The results showed that a majority of the participants did not feel safe or comfortable while they were walking or cycling on the shared space. A great number of participants also found the shared street chaotic for walking and cycling. With respect to using micromobility, a majority 
TABLE 1: Survey questions and units.

\begin{tabular}{|c|c|c|}
\hline Parameters & Survey questions & Units \\
\hline Gender & Please specify your gender & Female/male \\
\hline Age group & Please specify your age group & $18-24 / 25-39 / 40-54 / 55-65 /$ over 65 \\
\hline Profession & Please specify your profession & Student/full time working/retired/others \\
\hline Road use frequency & How often do you use Via Maqueda? & $\begin{array}{l}\text { Rarely/once a week/two to three times a week/four times a } \\
\text { week/every day }\end{array}$ \\
\hline $\begin{array}{l}\text { Perception of } \\
\text { infrastructure }\end{array}$ & $\begin{array}{c}\text { How do you evaluate the level of service of } \\
\text { infrastructure? }\end{array}$ & $\begin{array}{l}\text { On a scale from a to } F \text {, where a corresponds to the best } \\
\text { possible score and } F \text { to the worst }\end{array}$ \\
\hline Safety perception & $\begin{array}{l}\text { How safe do you think the Via Maqueda is by traveling } \\
\text { by walking/cycling/micromobility? }\end{array}$ & $\begin{array}{l}\text { Likert scale from } 1 \text { to } 5 \text {, where } 1 \text { corresponds to } \\
\text { completely negative and } 5 \text { to completely positive }\end{array}$ \\
\hline Comfort perception & $\begin{array}{c}\text { How comfortable do you think is Via Maqueda by } \\
\text { walking/cycling/micromobility? }\end{array}$ & $\begin{array}{l}\text { Likert scale from } 1 \text { to } 5 \text {, where } 1 \text { corresponds to } \\
\text { completely negative and } 5 \text { to completely positive }\end{array}$ \\
\hline Chaos perception & $\begin{array}{l}\text { How chaotic do you think is Via Maqueda by walking/ } \\
\text { cycling/micromobility? }\end{array}$ & $\begin{array}{l}\text { Likert scale from } 1 \text { to } 5 \text {, where } 1 \text { corresponds to } \\
\text { completely negative and } 5 \text { to completely positive }\end{array}$ \\
\hline
\end{tabular}

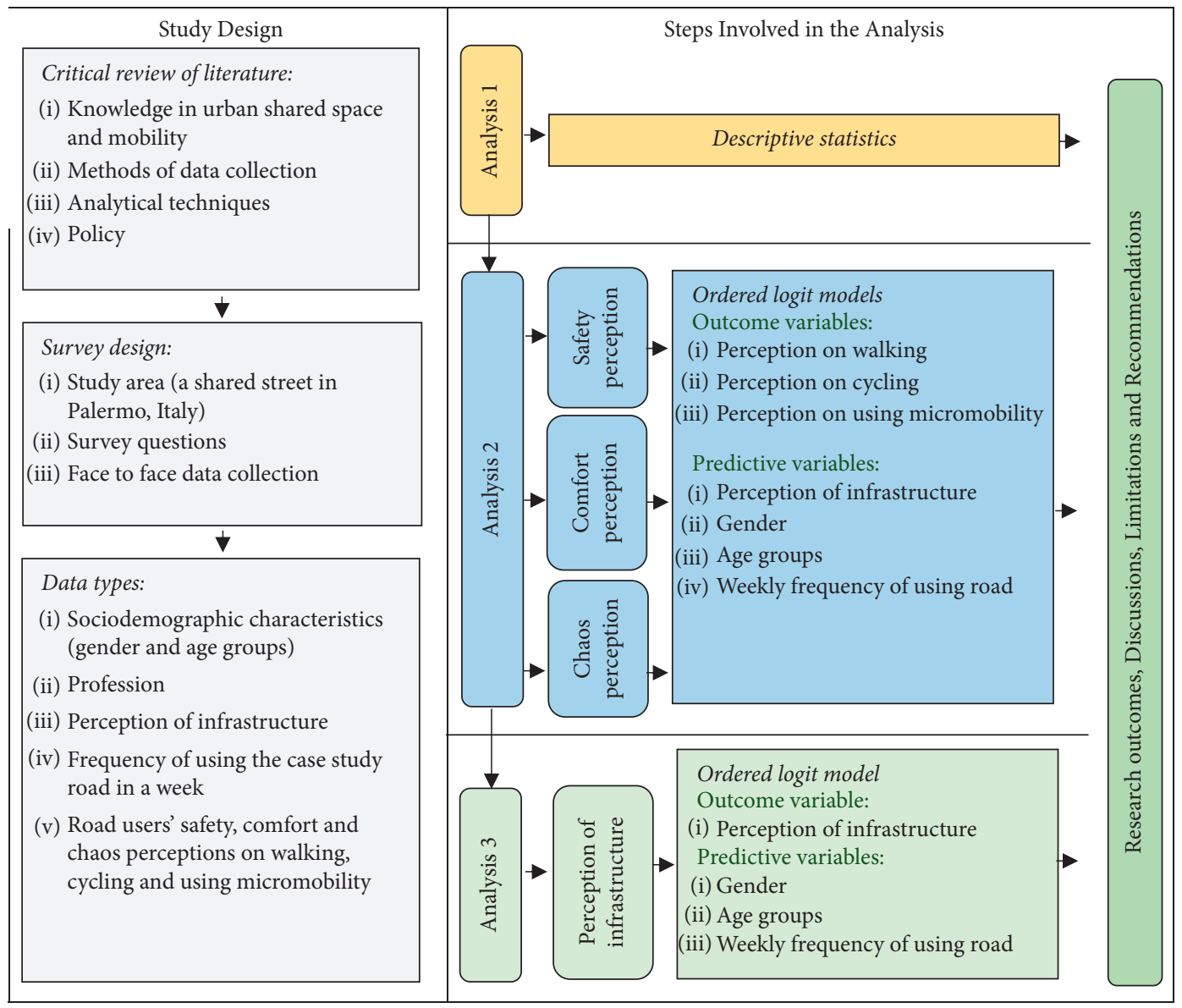

Figure 2: Methodological framework.

of the participants stated that safety and comfort were of some concern on the shared street. However, road user perception on chaos for using micromobility had a response of approximately $63.5 \%$ over level 4 . This suggested that participants did not seem to show any significant concerns on finding the shared street as chaotic, but they found that the shared street might not be comfortable and safe. The outcome revealed that a further investigation was needed in order to understand the reason for these causes.
The second step of the statistical approach was to carry out the ordered logit models. The first ordered logit model, which investigated the safety perception, suggested that one unit increase in perception of infrastructure improved the level of safety perception in walking by $65 \%$ (Table 3 ). Females were less likely to feel safe while walking on the shared street. With respect to cycling, participants had a safe feeling while cycling on shared streets when they find the perception of infrastructure was higher (odds ratio 1.36). Higher age 
TABLE 2: Descriptive statistics of variables.

\begin{tabular}{|c|c|}
\hline Variables & Units and frequency \\
\hline $\begin{array}{l}\text { Perception of } \\
\text { infrastructure }\end{array}$ & $F=1(0.5 \%) ; E=5(2.5 \%) ; D=28(14 \%) ; C=67(33.5 \%) ; B=86(43 \%) ; A=13(6.5 \%)$ \\
\hline Gender & Female $=94(47 \%) ;$ male $=106(53 \%)$ \\
\hline Age group & Over $65=21(10.5 \%) ; 55-65=42(21.5 \%) ; 40-54=72(36 \%) ; 25-39=53(26.5 \%) ; 18-24=11(5.5 \%)$ \\
\hline Profession & Student $=29(14.5 \%) ;$ full-time working $=112(56 \%) ;$ retired $=51(25.5) ;$ others $=8(4 \%)$ \\
\hline Road use frequency & $\begin{array}{c}\text { Rarely }=4(2 \%) \text {; once a week }=12(6 \%) \text {; two to three times a week }=29(14.5 \%) \text {; four times a week }=74(37 \%) \text {; } \\
\text { every day }=81(40.5 \%)\end{array}$ \\
\hline \multicolumn{2}{|c|}{ Safety perception (Likert scale) } \\
\hline Walking & $1=20(10 \%) ; 2=89(44.5 \%) ; 3=86(43 \%) ; 4=5(2.5 \%)$ \\
\hline Cycling & $1=36(18 \%) ; 2=109(54.5 \%) ; 3=51(25.5 \%) ; 4=4(2 \%)$ \\
\hline Using micromobility & $1=7(3.5 \%) ; 2=68(34 \%) ; 3=97(48.5 \%) ; 4=26(13 \%) ; 5=2(1 \%)$ \\
\hline \multicolumn{2}{|c|}{ Comfort perception (Likert scale) } \\
\hline Walking & $1=4(2 \%) ; 2=59(29.5 \%) ; 3=92(46 \%) ; 4=44(22 \%) ; 5=1(0.5 \%)$ \\
\hline Cycling & $1=17(8.5 \%) ; 2=80(40 \%) ; 3=86(43 \%) ; 4=16(8 \%) ; 5=1(0.5 \%)$ \\
\hline Using micromobility & $1=18(9 \%) ; 2=47(23.5 \%) ; 3=80(40 \%) ; 4=49(24.5 \%) ; 5=6(3 \%)$ \\
\hline \multicolumn{2}{|c|}{ Chaos perception (Likert scale) } \\
\hline Walking & $1=0 ; 2=11(5.5 \%) ; 3=62(31 \%) ; 4=96(48 \%) ; 5=31(15.5 \%)$ \\
\hline Cycling & $1=0 ; 2=17(8.5 \%) ; 3=57(28.5 \%) ; 4=70(35 \%) ; 5=56(28 \%)$ \\
\hline Using micromobility & $1=2(1 \%) ; 2=19(9.5 \%) ; 3=52(26 \%) ; 4=76(38 \%) ; 5=51(25.5 \%)$ \\
\hline
\end{tabular}

TABLE 3: Ordered logit models for safety perception.

\begin{tabular}{|c|c|c|c|c|c|}
\hline \multirow[t]{2}{*}{ Variables } & \multirow[t]{2}{*}{ Coefficient } & \multirow[t]{2}{*}{$P$ value } & \multirow[t]{2}{*}{ Odds ratio } & \multicolumn{2}{|c|}{$\begin{array}{l}95 \% \text { confidence interval } \\
\text { for odds ratio }\end{array}$} \\
\hline & & & & Lower & Upper \\
\hline \multicolumn{6}{|l|}{ Model 1. Walking } \\
\hline Perception of infrastructure & 0.50 & $\leq 0.001^{*}$ & 1.65 & 1.20 & 2.25 \\
\hline Gender & 0.67 & $0.02^{*}$ & 1.96 & 1.13 & 3.41 \\
\hline Age group & -0.30 & $0.03^{*}$ & 0.74 & 0.57 & 0.96 \\
\hline Road use frequency & 0.19 & 0.18 & 1.21 & 0.92 & 1.59 \\
\hline \multicolumn{6}{|l|}{ Model 2. Cycling } \\
\hline Perception of infrastructure & 0.31 & $0.04^{*}$ & 1.36 & 1.02 & 1.82 \\
\hline Gender & 0.28 & 0.32 & 1.32 & 0.77 & 2.28 \\
\hline Age group & 0.98 & 0.45 & 1.10 & 0.85 & 1.42 \\
\hline Road use frequency & 0.34 & $0.02^{*}$ & 1.40 & 1.07 & 1.84 \\
\hline \multicolumn{6}{|l|}{ Model 3. Using micromobility } \\
\hline Perception of infrastructure & 0.13 & 0.35 & 1.14 & 0.86 & 1.51 \\
\hline Gender & -0.10 & 0.72 & 0.91 & 0.53 & 1.55 \\
\hline Age group & -0.18 & 0.16 & 0.83 & 0.64 & 1.07 \\
\hline Road use frequency & -0.27 & $0.05^{*}$ & 0.76 & 0.58 & 1.00 \\
\hline
\end{tabular}

${ }^{*}$ Statistically significant at $95 \%$ confidence level.

groups rated the shared streets as an unsafe place for walking more likely than younger age groups. The predictive margins for safety perceptions including statistically significant predictor variables at $95 \%$ confidence level are given in Figure 3. The outcome referred to each Likert scale answer for each safety perception category. For instance, the likelihood of choosing safety perception 3 (outcome 3 ) increases with an increase in perception of infrastructure while likelihood of choosing safety perception 1 (outcome 1) decreases with the increasing perception of infrastructure.

The influence of perception of infrastructure on comfort perceptions of walking and cycling was statistically significant with odds ratios of 1.32 and 1.41 , respectively (Table 4). This suggested that one unit increase in perception of infrastructure decreased participants' uncomfortable feelings for walking by $32 \%$ or cycling by $41 \%$. The micromobility users' comfort perception improved by $19 \%$ by one unit increase in perception of infrastructure; however, the statistical significance level was higher than 0.05 . Therefore, this result should be examined with higher number of participants at different case study areas.

Participants who had been using the case study street more frequently stated that they had been more likely to feel comfortable during cycling in a shared street. One unit increase in age group decreases the comfort perception for walking in shared streets by 0.77 odds ratio. Higher age groups found walking on shared streets as an uncomfortable environment compared to younger age groups. 

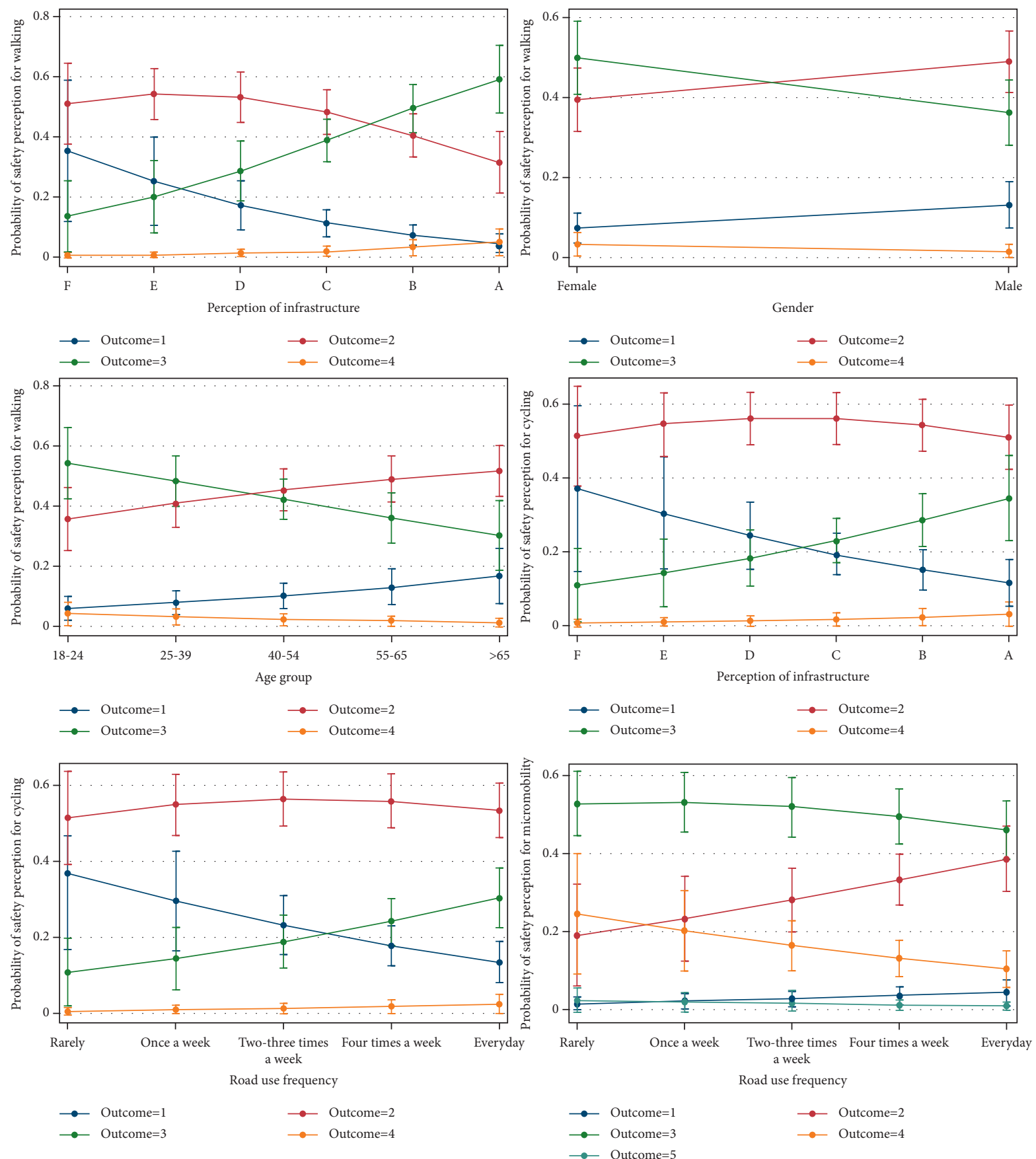

Figure 3: Predictive margins for safety perception at $95 \%$ confidence interval.

Male participants were more likely to find the shared streets as a comfortable environment than females in using micromobility (odds ratio 0.31). One unit increase in the age group will increase the comfort perception for using micromobility with 1.41 odds ratio. It should be noted in here that the majority of the participants were aged between 25 and 55. Therefore, predictive margins should be considered while discussing the results. The predictive margins for comfort perceptions, including statistically significant predictor variables at 95\% confidence level, are given in Figure 4.

According to the participants, one unit increase in perception of infrastructure increased the chaos perception by
$47 \%$ at shared spaces while walking (Table 5). Road users suggested that a higher level of shared space infrastructure provided a more chaotic environment for walking. This result could be attributed to the fact that the Via Maqueda Street was highly dense and any infrastructural improvement could increase chaos perception for pedestrians while it could decrease chaos perception by higher perception of infrastructure for cyclists and micromobility users. Therefore, there was a tradeoff between chaos perception of pedestrians and perception of infrastructure at dense streets, and this emerged the importance of optimal planning methodology for all road users while improving the infrastructure at shared spaces. 
TABLE 4: Ordered logit models for comfort perception.

\begin{tabular}{|c|c|c|c|c|c|}
\hline \multirow[t]{2}{*}{ Variables } & \multirow[t]{2}{*}{ Coefficient } & \multirow[t]{2}{*}{$P$ value } & \multirow[t]{2}{*}{ Odds ratio } & \multicolumn{2}{|c|}{$\begin{array}{l}\text { 95\% confidence interval } \\
\text { for odds ratio }\end{array}$} \\
\hline & & & & Lower & Upper \\
\hline \multicolumn{6}{|l|}{ Model 1. Walking } \\
\hline Perception of infrastructure & 0.27 & $0.05^{* *}$ & 1.32 & 1.00 & 1.74 \\
\hline Gender & 0.27 & 0.32 & 1.31 & 0.77 & 2.22 \\
\hline Age groups & -0.26 & $0.04^{* *}$ & 0.77 & 0.60 & 0.99 \\
\hline Road use frequency & -0.02 & 0.86 & 0.98 & 0.75 & 1.27 \\
\hline \multicolumn{6}{|l|}{ Model 2. Cycling } \\
\hline Perception of infrastructure & 0.34 & $0.02^{* *}$ & 1.41 & 1.05 & 1.89 \\
\hline Gender & 0.43 & 0.12 & 1.54 & 0.90 & 2.64 \\
\hline Age groups & -0.13 & 0.33 & 0.88 & 0.68 & 1.14 \\
\hline Road use frequency & 0.34 & $0.02^{* *}$ & 1.40 & 1.07 & 1.84 \\
\hline \multicolumn{6}{|l|}{ Model 3. Using micromobility } \\
\hline Perception of infrastructure & 0.18 & 0.20 & 1.19 & 0.91 & 1.56 \\
\hline Gender & -1.16 & $\leq 0.001^{* *}$ & 0.31 & 0.18 & 0.54 \\
\hline Age groups & 0.35 & $0.01^{* *}$ & 1.41 & 1.10 & 1.81 \\
\hline Road use frequency & -0.24 & $0.07^{*}$ & 0.79 & 0.61 & 1.02 \\
\hline
\end{tabular}

${ }^{*}$ Statistically significant at $90 \%$ confidence level. ${ }^{* *}$ Statistically significant at $95 \%$ confidence level.

Regarding gender, males responded that walking on an urban shared space was more chaotic compared to females (odds ratio 2.62). The predictive margins for chaos perceptions including statistically significant predictor variables at $95 \%$ confidence level are given in Figure 5.

The following analysis investigated the relationship between sociodemographic characteristics and perception of infrastructure. A predictive analysis using the ordered logit model was applied (Table 6). The results revealed that none of the predictor variables were statistically significant at $95 \%$ confidence level. Only road use frequency was statistically significant at $90 \%$ confidence level. This suggested that the more road users were familiar with the road infrastructure, and the more they perceived the higher the perception of infrastructure. The following section provides the discussion of the given results.

\section{Discussion}

Shared space is a novel concept to create a sustainable urban design for promoting active travel modes (i.e., walking, cycling, and micromobility). However, safety and comfort appear to emerge as critical when using active travel modes at shared spaces/streets. These issues are barriers for encouraging people to walk, cycle, and use micromobility at shared spaces. This research area is increasingly becoming important and there is still a need to discover the reasons behind these problems. The characteristics of road users' perceptions are not well understood in previous research, and consequently, safety, comfort, and chaos issues remain as vital aspects that require further investigation. Therefore, this study aims to investigate the influences on safety, comfort, and chaos perceptions for active travel modes with attention to walking, cycling, and micromobility at shared spaces. Firstly, and most importantly, the research addresses a significant gap in the literature. The novel survey and analytical approach provide a deeper understanding of safety, comfort, and chaos issues at shared spaces. Due to the application of a rigorous methodological approach and the lack of similar studies being carried out in the past, a direct comparison of the results with the state-of-the-art review is not straightforward; consequently, the outcomes are discussed carefully and critically.

About $77.5 \%$ of the road users who participated in this survey travel frequently in the case study area. Approximately, $84 \%$ of the participants state that their perception of infrastructure was equal to or above level C. However, the percentage of participants who rated it as Level $\mathrm{A}$ is $6.5 \%$. This suggests that the infrastructure of the shared case study space is moderate but still has issues based on participants' perceptions. Safety and comfort parameters are statistically significant at shared spaces for walking and cycling travel modes. These descriptive statistics show that there is a consistency between the collected survey data and the arguments in the state-of-the-art review about the comfort problems at shared spaces $[3,16,17]$. This study also suggests that a great number of participants found the shared spaces chaotic for walking and cycling. Regarding the micromobility, the participants did not feel that paths are chaotic but were unsafe and uncomfortable. The outcomes related to micromobility use on shared spaces need a further investigation in order to understand the reasons behind safety and comfort issues.

The results by ordered logit models in this study point out that a higher perception of infrastructure increases safety perceptions for walking at shared spaces. This result is consistent with the arguments in the literature [21] implicitly. Zheng et al. [21] underline that physical barriers, such as vendor booths or garbage bins, limit the pedestrian movements and increase the violation by pedestrians. However, this information in the literature is not sufficient to explain the relationship between perception of infrastructure and safety perception for walking. The predicted outcomes in this study suggest that one unit increase in age groups decreases the level of safety perception for walking at shared spaces. Also, males feel safer compared to females 

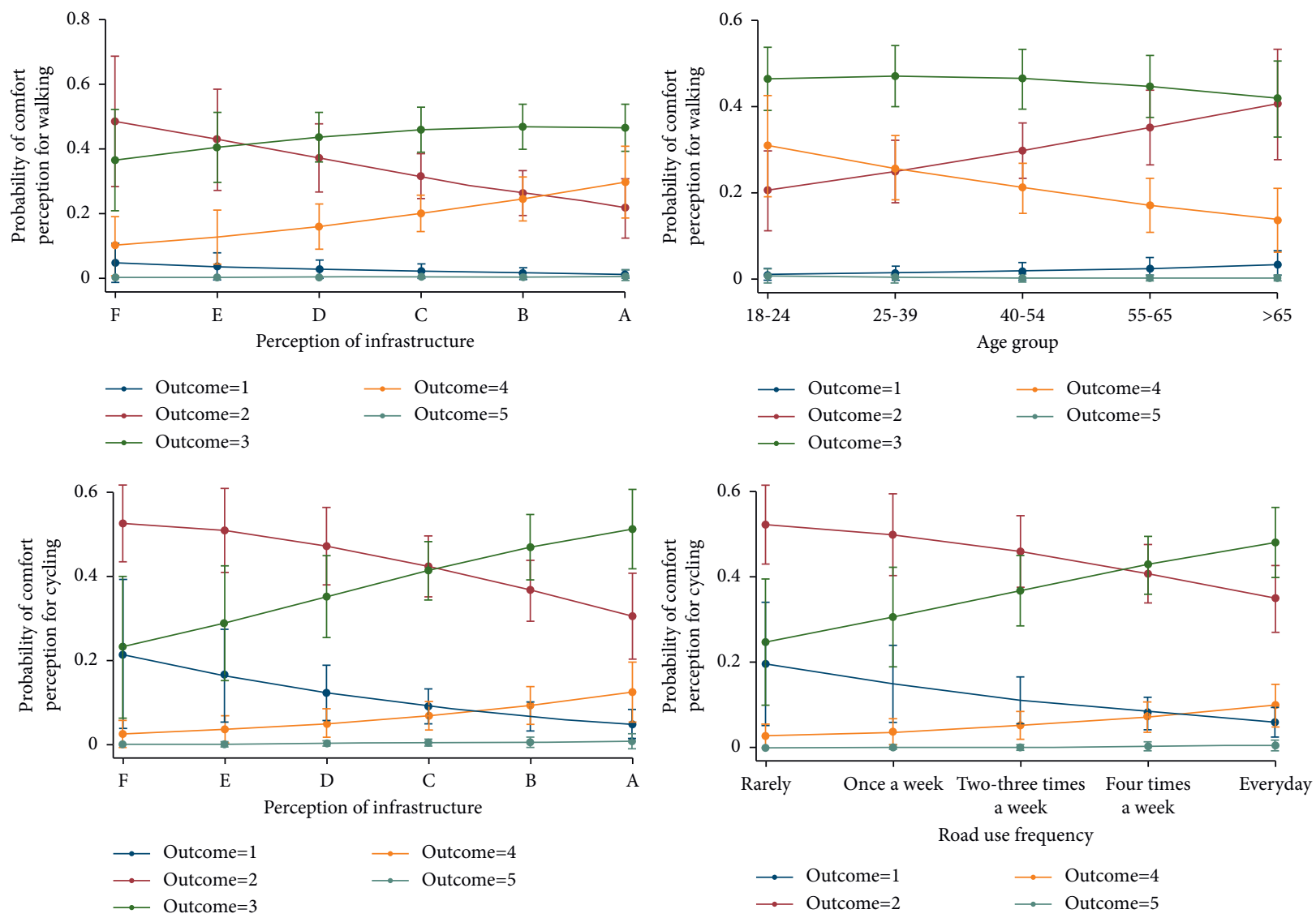

$\because$ Outcome $=2$
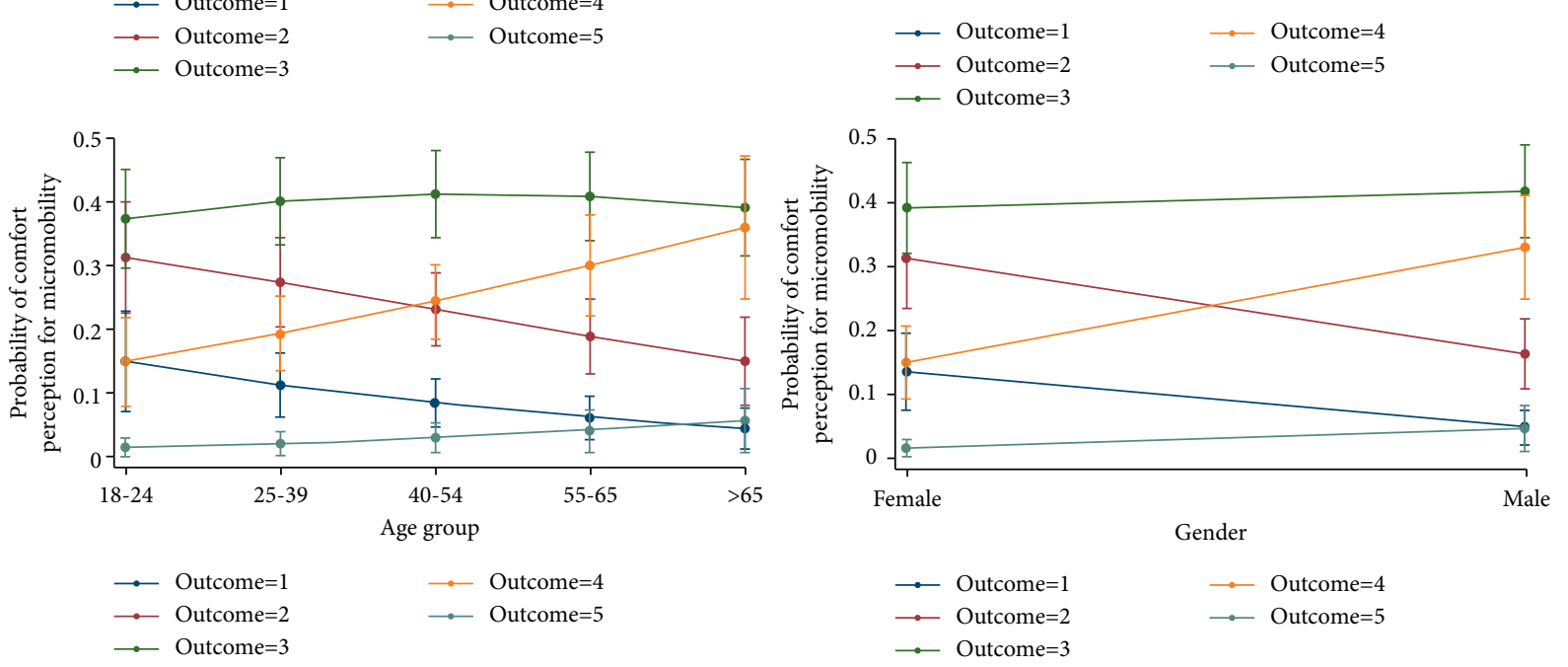

FIgURE 4: Predictive margins for comfort perception at $95 \%$ confidence interval.

while walking at shared spaces. In addition, one unit increase in perception of infrastructure improves the safety perception for cycling. Regarding the literature, it is well known that cyclists' speeding and failure to keep a distance [20], and pedestrians' failure to pay attention [3] cause safety problems. This suggests that a further analysis of speeding and yielding behaviours in different shared space areas for each age group and gender emerges as being essential to investigate the relationship between road users' behaviour and safety perceptions. Moreover, the impact of perception of infrastructure on cyclists' behaviour on keeping a distance with other road users should be investigated in more detail.
A study carried out by Kaparias et al. [18] showed that a good level of infrastructure is important for the comfort perception of pedestrians using shared spaces, and it is also shown that the negative attitude of pedestrians towards cyclists in shared spaces would be eliminated if the infrastructure is designed adequately [19]. However, identifying to what extent the infrastructure plays a role in improving comfort perception has not been widely understood. The outcomes in this study fill this gap by predicting the impact of perception of infrastructure on level of comfort perception. One-unit higher perception of infrastructure statistically and significantly increases the level of comfort 
TABLE 5: Ordered logit models for chaos perception.

\begin{tabular}{|c|c|c|c|c|c|}
\hline \multirow[t]{2}{*}{ Variables } & \multirow[t]{2}{*}{ Coefficient } & \multirow[t]{2}{*}{$P$ value } & \multirow[t]{2}{*}{ Odds ratio } & \multicolumn{2}{|c|}{$\begin{array}{l}95 \% \text { confidence interval } \\
\text { for odds ratio }\end{array}$} \\
\hline & & & & Lower & Upper \\
\hline \multicolumn{6}{|l|}{ Model 1. Walking } \\
\hline Perception of infrastructure & 0.38 & $0.01^{* *}$ & 1.47 & 1.08 & 1.98 \\
\hline Gender & 0.96 & $\leq 0.001^{* *}$ & 2.62 & 1.50 & 4.56 \\
\hline Age groups & -0.11 & 0.37 & 0.89 & 0.70 & 1.15 \\
\hline Road use frequency & 0.25 & $0.07^{*}$ & 1.28 & 0.98 & 1.68 \\
\hline \multicolumn{6}{|l|}{ Model 2. Cycling } \\
\hline Perception of infrastructure & -0.41 & $0.06^{*}$ & 0.66 & 0.50 & 0.88 \\
\hline Gender & 0.37 & 0.16 & 1.45 & 0.86 & 2.42 \\
\hline Age groups & 0.08 & 0.50 & 1.08 & 0.86 & 1.37 \\
\hline Road use frequency & 0.14 & 0.33 & 1.14 & 0.87 & 1.50 \\
\hline \multicolumn{6}{|l|}{ Model 3. Using micromobility } \\
\hline Perception of infrastructure & -0.18 & 0.19 & 0.83 & 0.64 & 1.09 \\
\hline Gender & -0.09 & 0.74 & 0.92 & 0.55 & 1.53 \\
\hline Age groups & -0.13 & 0.31 & 0.88 & 0.68 & 1.13 \\
\hline Road use frequency & -0.23 & $0.09^{*}$ & 0.80 & 0.62 & 1.03 \\
\hline
\end{tabular}

${ }^{*}$ Statistically significant at $90 \%$ confidence level. ${ }^{* *}$ Statistically significant at $95 \%$ confidence level.
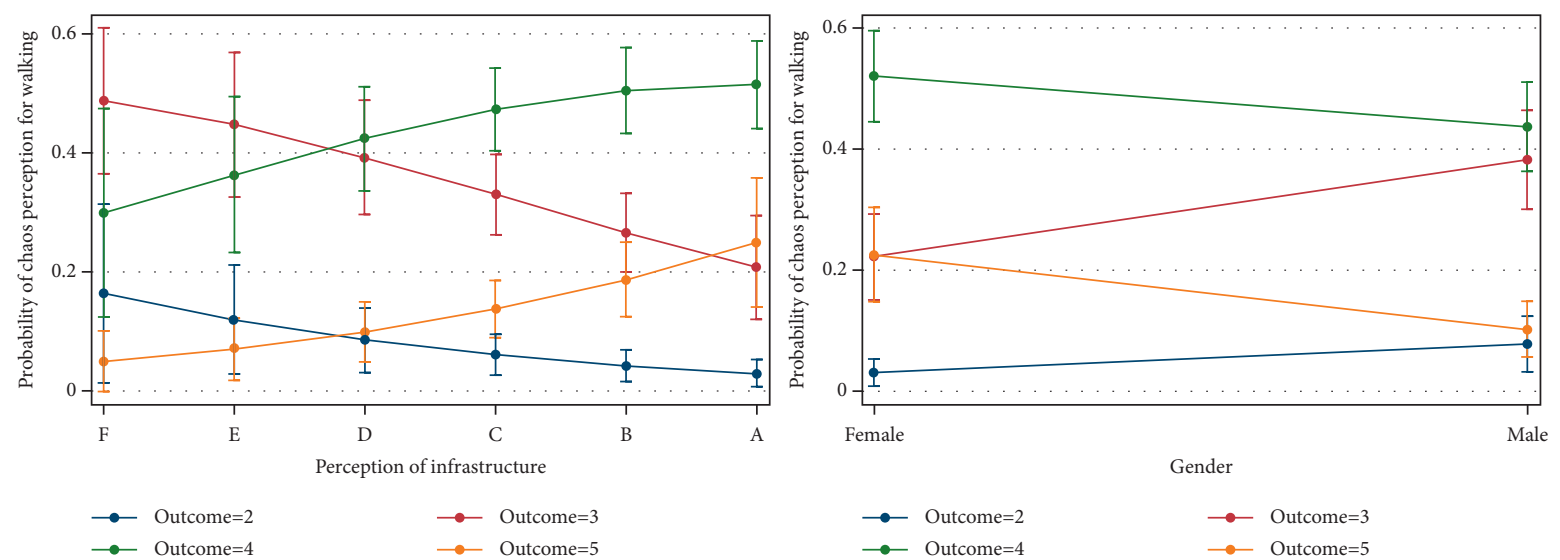

Figure 5: Predictive margins for chaos perception at 95\% confidence interval.

TABLE 6: Ordered logit models for perception of infrastructure.

\begin{tabular}{lccccc}
\hline Variables & Coefficient & $\begin{array}{c}P \\
\text { value }\end{array}$ & $\begin{array}{c}\text { Odds } \\
\text { ratio }\end{array}$ & $\begin{array}{c}95 \% \\
\text { confidence } \\
\text { interval for } \\
\text { odds ratio } \\
\text { Lower }\end{array}$ & Upper \\
\hline $\begin{array}{l}\text { Gender } \\
\text { Age groups }\end{array}$ & 0.34 & 0.21 & 1.41 & 0.83 & 2.38 \\
$\begin{array}{l}\text { Road use } \\
\text { frequency }\end{array}$ & 0.01 & 0.93 & 1.01 & 0.78 & 1.31 \\
\hline
\end{tabular}

${ }^{*}$ Statistically significant at $90 \%$ confidence level.

perception for walking by $32 \%$ and for cycling by $41 \%$. An increase in comfort perception occurs by the higher unit of perception of infrastructure; however, a significantly sharp increase is an outstanding result. Therefore, further studies are required to determine exactly how the perception of infrastructure affects comfort perception through a comparative analysis and/or at a different case study area. Not only perception of infrastructure but also age and frequency of using the shared spaces have an influence on comfort perception for walking and cycling, respectively. Besides the perception of infrastructure, future studies should also consider these parameters in the analysis to gain a deeper understanding. In addition, it is argued in the literature [23] that the increase of micromobility use on shared spaces also causes several discomforts and unsafe situations for active travellers, particularly pedestrians. Hence, the interaction between active travel modes at different shared space areas emerges as an important topic to be investigated.

Contrary to expectations $[22,26]$, perception of infrastructure and frequency of road use do not have an impact on comfort perception for using micromobility. Only gender and age groups statistically and significantly influence the level of comfort perception. It can be concluded that perception of infrastructure is an important parameter for predicting the comfort feelings for pedestrians and cyclists, but not for micromobility users in this case study street. It should be noted in here that the case study area has segregated marked paths for walking and cycling. However, the street does not have an infrastructural limitation for 
micromobility users which may bring them a flexibility. Further experimental investigations (i.e., yielding behaviour, trajectory, and segregation), along with consideration of different shared space areas, are needed to explore this issue.

Regarding the chaos perception, pedestrians stated that shared spaces are less chaotic when the perception of infrastructure is higher. Also, males found the shared spaces more chaotic than females. The results are new in the stateof-the-art review; therefore, it is not possible to compare with former knowledge. The outcomes should be validated by a larger sample size.

The last section of the analysis aims to explore the impact of gender, age, and road use frequency on the perception of infrastructure. The result shows that there is no relationship between the considered predictive variables and perception of infrastructure. This result is not expected with respect to the former study [9]. However, it is worthwhile noting that different case study areas show different characteristics due to the different policies and cultural circumstances [54]. On a wider level, research is needed to validate the outcomes, considering more responses in surveys in different case study areas.

As stated in the introduction, the research in this study is conducted in order to enhance the level of safety and comfort perceptions and reduce the chaos perception at shared spaces for active travel modes. The findings are very encouraging; however, the study has limitations. The data were collected from 200 participants who had been living in the case study area and using all three active travel modes of walking, cycling, and micromobility. It is difficult to find a shared space user who has experience in these three types of travel modes, particularly in a small town, and has a deeper knowledge and understanding. However, the results in this study are promising and should be validated by a larger sample size. In addition, road use frequency was considered in the model in order to quantify the familiarity of road users with the Via Maqueda street. However, including the frequency of using the three modes can be considered in a further survey-based study and a statistical multilevel modelling approach can be applied. Moreover, research, which compares the perception of single- and three-mode users, should be carried out in order to explore the impact of having deeper knowledge and experience on different travel modes for further perception-related studies. The outcomes, the methodology, and the applied analytical approach set a ground for future studies and are fundamentally important for decision-makers.

\section{Conclusion}

Shared spaces become a key element of sustainable urban transport recently since these infrastructures help to reduce traffic congestion and to mitigate road transport emissions. However, understanding road users' perceptions is important in improving the active use of shared spaces because different types of road users may have different expectations. In this work, the road users' safety, comfort, and chaos perceptions on Via Maqueda shared street are analysed by considering the impacts of perception of infrastructure, sociodemographic characteristics, and frequency of active travel. A face-to-face survey was carried out and ordered logit models were built to predict road user behaviours. The results of this study can be summarized as follows:

(i) Road users found the Via Maqueda Street unsafe and uncomfortable for walking, cycling, and using micromobility.

(ii) If the road users' perception of infrastructure is high, they feel safer and more comfortable at the shared space. Therefore, if it is aimed to encourage the active travel at shared spaces considering road users' perception of infrastructure becomes essential.

(iii) Road users stated that an increase in their perception of infrastructure makes the shared street more chaotic for walking, which implies that an optimal level of infrastructure is necessary to encourage pedestrians for using the shared space.

(iv) Frequent use of the shared street increases the safety perception of users for cycling.

(v) Gender has an impact on perceptions. Male users tend to describe the shared street as safe for walking and comfortable for using micromobility more than female users, while females found walking to be chaotic less than males.

(vi) Older road users tend to find the shared street to be unsafe and uncomfortable more than younger age groups.

\section{Data Availability}

The data used to support the findings of this study have not been made available because it is planned to use this data in future publications.

\section{Conflicts of Interest}

No potential conflicts of interest are reported by the authors.

\section{References}

[1] H. Delaney, G. Parkhurst, and S. Melia, "Walking and cycling on shared-use paths: the user perspective," Proceedings of the Institution of Civil Engineers - Municipal Engineer, vol. 170, no. 3, pp. 175-184, 2017.

[2] A. Karndacharuk, D. J. Wilson, and R. Dunn, "A review of the evolution of shared (street) space concepts in urban environments," Transport Reviews, vol. 34, no. 2, pp. 190-220, 2014.

[3] F. Gkekas, A. Bigazzi, and G. Gill, "Perceived safety and experienced incidents between pedestrians and cyclists in a high-volume non-motorized shared space," Transportation Research Interdisciplinary Perspectives, vol. 4, Article ID 100094, 2020.

[4] I. Kaparias, M. G. H. Bell, W. Dong et al., "Analysis of pedestrian-vehicle traffic conflicts in street designs with elements of shared space," Transportation Research Record: Journal of the Transportation Research Board, vol. 2393, no. 1, pp. 21-30, 2013. 
[5] E. Clarke, "Shared space-the alternative approach to calming traffic," Traffic Engineering and Control, vol. 47, no. 8, pp. 290-292, 2006.

[6] C. Frosch, D. Martinelli, and A. Unnikrishnan, "Evaluation of shared space to reduce traffic congestion," Journal of Advanced Transportation, vol. 2019, Article ID 6510396, 2019.

[7] B. Hamilton-Baillie, "Shared space: reconciling people, places and traffic," Built Environment, vol. 34, no. 2, pp. 161-181, 2008.

[8] A. Karndacharuk, D. J. Wilson, and R. C. M. Dunn, "Analysis of pedestrian performance in shared-space environments," Transportation Research Record: Journal of the Transportation Research Board, vol. 2393, no. 1, pp. 1-11, 2013.

[9] A. Nikiforiadis, S. Basbas, and M. I. Garyfalou, "A methodology for the assessment of pedestrians-cyclists shared space level of service," Journal of Cleaner Production, vol. 254, Article ID 120172, 2020.

[10] A. L. Dannenberg, K. Kraft, and S. Alvanides, "Special issue editorial: tools and practices for understanding and promoting walking and walkability," Journal of Transport \& Health, vol. 5, pp. 1-4, 2017.

[11] T. A. Litman, Evaluating Active Transport Benefits and Costs: Guide to Valuing Walking and Cycling Improvements and Encouragement Programs, Victoria Transport Policy Institute, Victoria, Canada, 2020.

[12] C. Mulley, R. Tyson, P. McCue, C. Rissel, and C. Munro, "Valuing active travel: including the health benefits of sustainable transport in transportation appraisal frameworks," Research in Transportation Business \& Management, vol. 7, pp. 27-34, 2013.

[13] P. Oja, S. Titze, A. Bauman et al., "Health benefits of cycling: a systematic review," Scandinavian Journal of Medicine and Science in Sports, vol. 21, no. 4, pp. 496-509, 2011.

[14] R. Alsaleh and T. Sayed, "Modeling pedestrian-cyclist interactions in shared space using inverse reinforcement learning," Transportation Research Part F: Traffic Psychology and Behaviour, vol. 70, pp. 37-57, 2020.

[15] E. Commission, "White paper: roadmap to a single European transport area - towards a competitive and resource efficient transport system," European Strategy for a Sustainable and Smart Mobility, vol. 25, pp. 113-144, 2011.

[16] E. Paschalidis, S. Basbas, I. Politis, and M. Prodromou, "“Put the blame on... others!": the battle of cyclists against pedestrians and car drivers at the urban environment. A cyclists' perception study," Transportation Research Part F: Traffic Psychology and Behaviour, vol. 41, pp. 243-260, 2016.

[17] R. G. Poulos, J. Hatfield, C. Rissel et al., "An exposure based study of crash and injury rates in a cohort of transport and recreational cyclists in New South Wales, Australia," Accident Analysis and Prevention, vol. 78, pp. 29-38, 2015.

[18] I. Kaparias, M. G. H. Bell, A. Miri, C. Chan, and B. Mount, "Analysing the perceptions of pedestrians and drivers to shared space," Transportation Research Part F: Traffic Psychology and Behaviour, vol. 15, no. 3, pp. 297-310, 2012.

[19] L. Kang and J. D. Fricker, "Sharing urban sidewalks with bicyclists? An exploratory analysis of pedestrian perceptions and attitudes," Transport Policy, vol. 49, pp. 216-225, 2016.

[20] J. Hatfield and P. Prabhakharan, "An investigation of behaviour and attitudes relevant to the user safety of pedestrian/ cyclist shared paths," Transportation Research Part F: Traffic Psychology and Behaviour, vol. 40, pp. 35-47, 2016.

[21] L. Zheng, T. Sayed, and Y. Guo, "Investigating factors that influence pedestrian and cyclist violations on shared use path: an observational study on the Brooklyn bridge promenade,"
International Journal of Sustainable Transportation, vol. 14, no. 7, pp. 503-512, 2020.

[22] S. Chong, R. Poulos, J. Olivier, W. L. Watson, and R. Grzebieta, "Relative injury severity among vulnerable nonmotorised road users: comparative analysis of injury arising from bicycle-motor vehicle and bicycle-pedestrian collisions," Accident Analysis and Prevention, vol. 42, no. 1, pp. 290-296, 2010.

[23] N. Sikka, C. Vila, M. Stratton, M. Ghassemi, and A. Pourmand, "Sharing the sidewalk: a case of e-scooter related pedestrian injury," The American Journal of Emergency Medicine, vol. 37, pp. 1807-e7, 2019.

[24] M. Che, K. M. Lum, and Y. D. Wong, "Users' attitudes on electric scooter riding speed on shared footpath: a virtual reality study," International Journal of Sustainable Transportation, vol. 15, no. 2, pp. 152-161, 2020.

[25] J. DiGioia, K. E. Watkins, Y. Xu, M. Rodgers, and R. Guensler, "Safety impacts of bicycle infrastructure: a critical review," Journal of Safety Research, vol. 61, pp. 105-119, 2017.

[26] A. Nikiforiadis and S. Basbas, "Can pedestrians and cyclists share the same space? The case of a city with low cycling levels and experience," Sustainable Cities and Society, vol. 46, Article ID 101453, 2019.

[27] D. Tan, W. Wang, J. Lu, and Y. Bian, "Research on methods of assessing pedestrian level of service for sidewalk," Journal of Transportation Systems Engineering and Information Technology, vol. 7, no. 5, pp. 74-79, 2007.

[28] L. Kang, Y. Xiong, and F. L. Mannering, "Statistical analysis of pedestrian perceptions of sidewalk level of service in the presence of bicycles," Transportation Research Part A: Policy and Practice, vol. 53, pp. 10-21, 2013.

[29] B. B. Park and C. Li, "An analytical approach for estimating the Highway capacity manual signalized intersection delay variability," Computer-Aided Civil and Infrastructure Engineering, vol. 26, no. 4, pp. 327-333, 2011.

[30] J. Parks, A. Tanaka, P. Ryus, C. M. Monsere, N. McNeil, and M. Goodno, "Assessment of three alternative bicycle infrastructure quality-of-service metrics," Transportation Research Record: Journal of the Transportation Research Board, vol. 2387, no. 1, pp. 56-65, 2013.

[31] V. P. Sisiopiku, J. Byrd, and A. Chittoor, "Application of levelof-service methods for evaluation of operations at pedestrian facilities," Transportation Research Record: Journal of the Transportation Research Board, vol. 2002, no. 1, pp. 117-124, 2007.

[32] P. Christopoulou and M. Pitsiava-Latinopoulou, "Development of a model for the estimation of pedestrian level of service in Greek urban areas," Procedia - Social and Behavioral Sciences, vol. 48, pp. 1691-1701, 2012.

[33] V. Sisiopiku, J. Byrd, and J. Waid, "Pedestrian level of service comparison," in Proceedings of the 11th World Conference on Transport Research, FEUP, Berkeley, CA, USA, June 2007.

[34] D. Carter, W. Hunter, C. Zegeer, J. Richard Stewart, and H. F. Huang, Pedestrian and Bicyclist Intersection Safety Indices: Final Report, Federal Highway Administration, McLean, VA, USA, 2006.

[35] A. Nikiforiadis, S. Basbas, F. Mikiki, A. Oikonomou, and E. Polymeroudi, "Pedestrians-cyclists shared spaces level of service: comparison of methodologies and critical discussion," Sustainability, vol. 13361 pages, 2021.

[36] D. M. P. Wedagama, S. Bennett, and D. Dissanayake, “Analyzing pedestrian perceptions towards traffic safety using discrete choice models," International Journal of Advanced 
Science, Engineering and Information Technology, vol. 10, no. 6, pp. 2394-2401, 2020.

[37] J. Speck, Walkable City: How Downtown Can Save America, One Step at A Time, Farrar, Straus and Giroux, New York, NY, USA, 2012.

[38] A. Rodriguez-Valencia, G. A. Barrero, H. A. Ortiz-Ramirez, and J. A. Vallejo-Borda, "Power of user perception on pedestrian quality of service," Transportation Research Record: Journal of the Transportation Research Board, vol. 2674, no. 5, pp. 250-258, 2020.

[39] J. Schröder, Face-to-Face Surveys. GESIS Survey Guidelines, Mannheim, Germany: GESIS-Leibniz, Institute for the Social Sciences, New Delhi, India, 2016.

[40] R. V. Krejcie and D. W. Morgan, "Determining sample size for research activities," Educational and Psychological Measurement, vol. 30, no. 3, pp. 607-610, 1970.

[41] "ISTAT," Demography in Figures, https://demo.istat.it/ popres/index.php?anno=2020\&lingua $=$ eng, 2020.

[42] M. L. D. Jalon, A. G. Ortega, and J. D. E. Curiel, "The social perception of urban transport in the city of Madrid: the application of the Servicescape Model to the bus and underground services," European Transport Research Review, vol. 11, no. 37, 2019.

[43] P. Bucsky, "Modal share changes due to COVID-19: the case of Budapest," Transportation Research Interdisciplinary Perspectives, vol. 8, Article ID 100141, 2020.

[44] B. W. Landis, V. R. Vattikuti, R. M. Ottenberg, D. S. McLeod, and M. Guttenplan, "Modeling the roadside walking environment: pedestrian level of service," Transportation Research Record: Journal of the Transportation Research Board, vol. 1773, no. 1, pp. 82-88, 2001.

[45] B. W. Landis, V. R. Vattikuti, and M. T. Brannick, "Real-time human perceptions: toward a bicycle level of service," Transportation Research Record: Journal of the Transportation Research Board, vol. 1578, no. 1, pp. 119-126, 1997.

[46] T. Campisi, N. Akgün, D. Ticali, and G. Tesoriere, "Exploring public opinion on personal mobility vehicle use: a case study in Palermo, Italy," Sustainability, vol. 12, no. 13, 5460 pages, 2020.

[47] R. D. McKelvey and W. Zavoina, "A statistical model for the analysis of ordinal level dependent variables," Journal of Mathematical Sociology, vol. 4, no. 1, pp. 103-120, 1975.

[48] C. Winship and R. D. Mare, "Regression models with ordinal variables," American Sociological Review, vol. 49, no. 4, pp. 512-525, 1984.

[49] S. Menard, Applied Logistic Regression Analysis, Sage Publications, USA, 2nd edition, 2002.

[50] T. Campisi, N. Akgün, and G. Tesoriere, "An ordered logit model for predicting the willingness of renting micro mobility in urban shared streets: a case study in Palermo, Italy," in Proceedings of the Computational Science and Its Applications-ICCSA 2020, pp. 796-808, Springer, Cham, Switzerland, October 2020.

[51] K. Kang and K. Lee, "Development of a bicycle level of service model from the user's perspective," KSCE Journal of Civil Engineering, vol. 16, no. 6, pp. 1032-1039, 2012.

[52] L. Bai, P. Liu, C.-Y. Chan, and Z. Li, "Estimating level of service of mid-block bicycle lanes considering mixed traffic flow," Transportation Research Part A: Policy and Practice, vol. 101, pp. 203-217, 2017.

[53] R. Bender and U. Grouven, "Ordinal logistic regression in medical research," Journal of the Royal College of Physicians of London, vol. 31, pp. 546-551, 1997.
[54] N. Akgün, S. Daniels, M. C. Bell, N. Nuyttens, N. Thorpe, and D. Dissanayake, "Exploring regional differences in cyclist safety at roundabouts: a comparative study between the UK (based on Northumbria data) and Belgium," Accident Anal$y$ sis and Prevention, vol. 150, Article ID 105902, 2021. 